\title{
Gestão Ambiental em Empreendimento de Engenharia (Construção Civil) na Cidade de Várzea Grande-MT: Estudo de Caso
}

\author{
Environmental Management In Enterprise Engineering (Civil \\ Construction) In The City Várzea Grande-MT: Case Study
}

\author{
${ }^{1}$ Edvan Oládio Neves da Silva, ${ }^{2}$ Ethienne Boa Sorte Carneiro, ${ }^{3}$ Maria Aparecida da Silva, ${ }^{4}$ Lizia Costa Martins de Almeida, \\ ${ }^{5}$ Renato Rodrigues Lima, ${ }^{6}$ Thalles Antunes Maciel Ribeiro \\ ${ }^{1232456}$ Discentes do curso de pós-graduação em Engenharia de Segurança do trabalho, Universidade \\ Federal de Mato Grosso-UFMT.
}

Recebido: jul 2015, Aceito: set 2015, publicado: out 2015

\begin{abstract}
Resumo: A preocupação com sustentabilidade no setor da construção civil está cada vez mais recorrente. Muitas construtoras já adotaram sistemas para reciclagem de materiais e investem na redução do uso de matérias-primas não renováveis. Esse conceito ecologicamente correto, além de trazer benefícios ao meio ambiente, também pode reduzir o custo da obra, aliando o reaproveitamento e a reciclagem de materiais. É uma prática que tem se tornado cada vez mais comum no setor e o número de construções verdes tem aumentado a cada ano. Muitas alternativas estão sendo utilizado para deixar a obra mais sustentável, como o uso da água da chuva, a implantação de novas tecnologias para aquecimento e geração de energia, tratamento de resíduos sólidos, além da utilização de materiais ecologicamente corretos. O objetivo desta análise é demonstrar a gestão ambiental de um empreendimento de engenharia que está sendo construído na cidade de Várzea Grande-MT.
\end{abstract}

Palavras-chave: Sustentabilidade; Empreendimento; Meio Ambiente; Resíduos, segurança em obras

\begin{abstract}
Concern for sustainability in the construction sector is increasingly recurring. Many construction companies have adopted systems to recycle materials and invest in reducing the use of nonrenewable raw materials. This environmentally friendly concept, and bring benefits to the environment, can also reduce the cost of the work, combining the reuse and recycling of materials. It is a practice that has become increasingly common in the industry and the number of green buildings has increased every year. Many alternatives are being used to make the most sustainable project, as the reuse of rainwater, the introduction of new technologies for heating and power generation, waste treatment, besides the use of environmentally friendly materials. The objective of this analysis is to demonstrate the environmental management of an enterprise engineering that is being built in the city of Varzea Grande-MT.
\end{abstract}

Keywords: Sustainability; enterprise; Environment; Waste.

\section{INTRODUÇÃO}

A preservação ambiental tem sido um tema amplamente discutido na sociedade moderna e assume um significado cada vez maior para as empresas. No campo da construção civil, o modo de produção usado pela maioria das empresas construtoras não era sustentável, ou seja, não aliavam o crescimento econômico com o respeito ao meioambiente (DEGANI, 2003). No entanto, o que tem ocorrido atualmente é um caminho de transformações na questão ambiental, pois se observa um grau de comprometimento maior entre empresários e administradores para solucionar problemas relacionados a produção, distribuição e consumo de bens e serviços (SOUZA, 2002).

Com o desenvolvimento do país, a migração do homem do campo para a cidade, o crescimento demográfico, as paisagens urbanas vão se modificando e surgem os aglomerados urbanos que exigem cada vez mais obras de engenharia, com isso é inevitável que ocorrem os impactos ambientais.

Entretanto, esses impactos podem ser compensados ou minimizados, para isso é necessário as 
intervenções públicas e a aplicação das normas vigentes.

Neste trabalho serão apresentadas as alternativas que estão sendo utilizadas em um empreendimento de engenharia que está sendo construído na cidade de Várzea Grande-MT. Serão discutidas as medidas tomadas pela empresa para tornar a obra mais sustentável, como o uso da água da chuva, a implantação de novas tecnologias para aquecimento e geração de energia, tratamento de resíduos sólidos, além da utilização de materiais ecologicamente corretos. $\mathrm{O}$ objetivo desta análise é justamente demonstrar a importância da gestão ambiental de um empreendimento de engenharia.

\section{REVISÃO BIBLIOGRÁFICA}

No Brasil, a questão dos resíduos gerados em ambientes urbanos atinge contornos gravíssimos, pela ínfima presença de soluções adequadas quer para os efluentes líquidos ou resíduos sólidos. Este não deixa de ser um quadro típico dos países em desenvolvimento, mas nem por isso deve permitir qualquer postura condescendente da sociedade.

A nova consciência ambiental que surgiu entre as décadas de 60 e 70 modificou os objetivos da organização e ampliou consideravelmente o conceito de administração, corroborando com a inclusão do Sistema de Gestão Ambiental ao sistema de gestão geral da empresa.

Segundo Kraemer (2004) a Gestão Ambiental compõe um aspecto da gestão empresarial que desenvolve e implanta as políticas e estratégias ambientais e cada vez mais as empresas vêm investindo nesse tipo de gestão, uma vez que o meio ambiente tem se mostrado como uma séria problemática além de se configurar como um objeto de estudo para o desenvolvimento do sistema de gestão ambiental.

- De acordo com Meyer (2000), a gestão ambiental é apresentada conforme a seguir: Objeto de manter o meio ambiente saudável (à medida do possível), para atender as necessidades humanas atuais, sem comprometer o atendimento das necessidades das gerações futuras.

Meio de atuar sobre as modificações causadas no meio ambiente pelo uso e/ou descarte empreendimento para deixar a obra mais sustentável, como o uso da água da chuva, a implantação de novas tecnologias para aquecimento e geração de energia, tratamento de resíduos sólidos, além da utilização de materiais ecologicamente corretos. O objetivo desta análise é demonstrar a gestão ambiental de um

- dos bens e detritos gerados pelas atividades humanas, a partir de um plano de ações viáveis, técnica e economicamente, com prioridades perfeitamente definidas.

- Objeto de manter o meio ambiente saudável (à medida do possível), para atender as necessidades humanas atuais, sem comprometer o atendimento das necessidades das gerações futuras.

- Meio de atuar sobre as modificações causadas no meio ambiente pelo uso e/ou descarte 
dos bens e detritos gerados pelas atividades humanas, a partir de um plano de ação viável, técnica e economicamente, com prioridades perfeitamente definidas.

- Instrumentos de monitoramentos, controles, taxações, imposições, subsídios, divulgação, obras e ações mitigadoras, além de treinamento e conscientização.

- Base de atuação de diagnósticos (cenários) ambientais da área de atuação, a partir de estudos e pesquisas dirigidos em busca de soluções para os problemas que forem detectados.

Os resíduos de construção e demolição são parte dos resíduos sólidos urbanos que incluem também os resíduos domiciliares com todos os problemas anteriormente relatados. Porém, para os resíduos de construção e demolição há agravantes: o profundo desconhecimento dos volumes gerados, dos impactos que eles causam, dos custos sociais envolvidos e, inclusive, das possibilidades de seu reaproveitamento fazem com que os gestores dos resíduos se apercebam da gravidade da situação unicamente nos momentos em que, acuados, vêem a ineficácia de suas ações corretivas.

Assim, esta pesquisa apresenta relevância social e científica, pois se percebe que a gestão ambiental tem se configurado como um instrumento importante e necessário no desenvolvimento de atividades relacionadas com todos os empreendimentos.

Nesse contexto, o objetivo deste estudo foi conhecer a gestão ambiental de um empreendimento de engenharia em fase de construção no município de Várzea Grande-MT.

\section{Meio Ambiente}

Na década de 80, de acordo com a Comissão Mundial Sobre Meio Ambiente (1988) surgiu o conceito de desenvolvimento sustentável propondo o atendimento das necessidades das gerações atuais sem comprometer $o$ atendimento das necessidades das futuras gerações.

Em concordância com Mayer (2000) o sistema de gestão é a gestão dos processos e produtos de uma empresa visando à proteção ambiental. Ao longo dos anos criou-se o conceito de que poluição é desperdício resultante de ineficiência tecnológica, onde esse residual gera lucro, havendo retorno de vendas, custos e imagem. Os Sistemas de Gestão Ambiental e a série de normas ISO 14000, conforme Nahuz (2000) são sistemas que estimulam a atitude proativa, onde são abordados: estrutura organizacional, as responsabilidades, as práticas, os procedimentos, os processos e recursos para aplicação, elaboração, revisão, manutenção e auditoria das políticas ambientais adotadas.

\section{Saneamento básico}

Segundo a Organização Mundial da Saúde o saneamento básico é o controle de todos os fatores do meio físico do homem que exercem efeitos deletérios sobre seu bem estar físico, mental ou social tendo a saúde pública o dever de promover, recuperar e proteger a saúde da população a partir da implantação de sistemas de abastecimento de água, esgotamento sanitário e manejo de resíduos, que trazem uma melhoria na qualidade de vida da população.

\section{Norma Regulamentadora-NR}

As NR são normas elaboradas pelo Ministério do Trabalho e Emprego. 
Foram criadas e devem ser observadas a fim de promover saúde e segurança do trabalho na empresa.

Nas obras civis precisam ser seguidas, além de outras, as normativas NR 4 - Serviços Especializados em Engenharia de Segurança, a NR 7 Programa de Controle Médico de Saúde Ocupacional, a NR 9 Programa de Prevenção de Riscos Ambientais, a NR 18 condições e meio ambiente de trabalho na indústria da construção e a NR 21 desenvolvimento de trabalho em céu aberto e a NR 35, trabalho em altura.

A NR 4 observa-se que o empreendedor pode fazer o dimensionamento dos Serviços Especializados em Engenharia de Segurança e em Medicina do Trabalho vinculada à gradação do risco da, atividade principal e ao número total de empregados do estabelecimento.

\footnotetext{
Conforme a NR 4 Para fins de dimensionamento, os canteiros de obras e as frentes de trabalho com menos de 1 (um) mil empregados e situados no mesmo estado, território ou Distrito Federal não serão considerados como estabelecimentos, mas como integrantes da empresa de engenharia principal responsável, a quem caberá organizar os Serviços Especializados em Engenharia de Segurança e em Medicina do Trabalho
}

Na NR n.8 são determinados os parâmetros para as edificações, observando as condições mínimas de conforto e segurança nos locais de trabalho como proteção contra intempéries e materiais adequados nos locais de circulação de colaboradores.

A NR 9, Programa de Prevenção de Riscos Ambientais essa norma visa manter o ambiente de trabalho das empresas livre de riscos para seus trabalhadores.

As condições e meio ambiente de trabalho na indústria da construção constam na NR 18. Tem por Objetivo e Campo de Aplicação entre outros, estabelecer diretrizes de ordem administrativa, de planejamento e de organização, que objetivam a implementação de medidas de controle e sistemas preventivos de segurança nos processos, nas condições e no meio ambiente de trabalho na Indústria da Construção.

$$
\begin{aligned}
& \text { Conforme esta NR no seu item } 18.1 .2 \\
& \text { " Consideram-se atividades da Indústria da } \\
& \text { Construção as constantes do Quadro I, Código da } \\
& \text { Atividade Específica, da NR } 4 \text { - Serviços } \\
& \text { Especializados em Engenharia de Segurança e } \\
& \text { em Medicina do Trabalho e as atividades e } \\
& \text { serviços de demolição, reparo, pintura, limpeza e } \\
& \text { manutenção de edifícios em geral, de qualquer } \\
& \text { número de pavimentos ou tipo de construção, } \\
& \text { inclusive manutenção de obras de urbanização e } \\
& \text { paisagismo". }
\end{aligned}
$$

Na NR n. 21 são definidas as exigências de abrigos que deve ser fornecida pela empresa aos seus colaboradores em locais de céu aberto, delimitando as exigências mínimas.

A NR 35 estabelece os requisitos mínimos e as medidas de proteção para o trabalho em altura, envolvendo o planejamento, a organização e a execução, de forma a garantir a segurança e a saúde dos trabalhadores envolvidos direta ou indiretamente com esta atividade.

Conforme a NR, item 35.1.2 Considera-se trabalho em altura toda atividade executada acima de 2,00 $\mathrm{m}$ (dois metros) do nível inferior, onde haja risco de queda.

\section{MATERIAIS E MÉTODOS}

Estudo desenvolvido foi por meio de observação in loco e descritivo, do tipo estudo de caso.

\section{Área de Estudo}

O local do estudo foi em uma empresa do ramo da construção civil no município de Várzea Grande-MT. O Município atualmente possui aproximadamente 250 mil habitantes correspondendo a quase $50 \%$ da população da capital, a localização de Várzea Grande no Brasil e em Mato Grosso são apresentadas nos mapas A e B da Figura 1. 
Figura 1: Mapa de localização

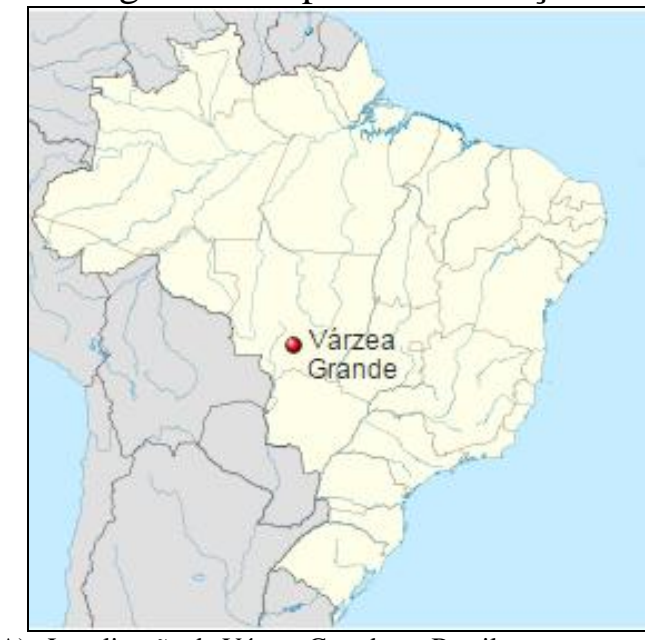

A) Localização de Várzea Grande no Brasil

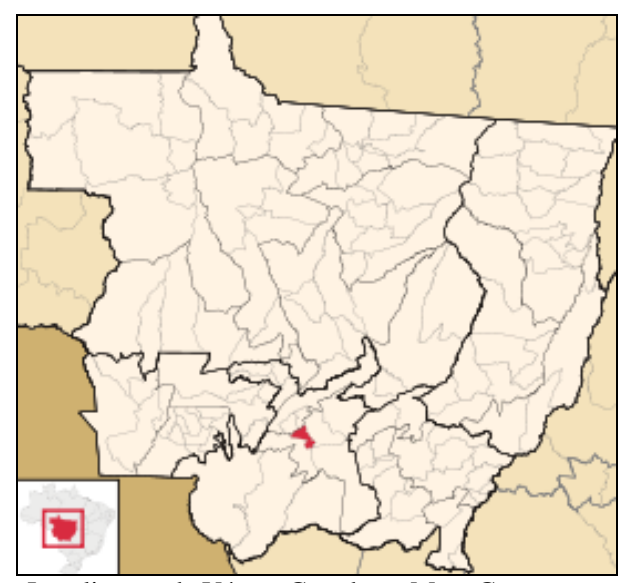

B) Localização de Várzea Grande no Mato Grosso

Várzea Grande é a segunda cidade mais populosa do estado de Mato Grosso, a $7^{\mathrm{a}}$ mais populosa do centro oeste, a $100^{\mathrm{a}}$ cidade mais populosa do Brasil e está em conurbação com Cuiabá, na qual é separada pelo Rio Cuiabá. Pertence à Região Metropolitana do Vale do Rio Cuiabá

\section{Local do empreendimento}

O espaço construído constará de um condomínio com três blocos de apartamentos residenciais, com 4 pavimentos, guarita, vestiários, depósito, espaço gourmet, espaçofitness, playground, piscinas, salão de festas, central de gás e percolado. O período de coleta dos dados correspondeu ao mês de julho de 2015.

Foi realizada uma visita técnica, cuja foi acompanhada pelo engenheiro responsável pela obra. Nesse momento, realizou-se registro fotográfico, um questionário respondido pelo engenheiro e observação da construção sendo anotadas todas as informações relevantes para o estudo.

A obra, atualmente, conta com aproximadamente 50 funcionários por dia. As refeições são terceirizadas, o canteiro de obras possui vestiários, refeitório e banheiros para os funcionários.

\section{RESULTADOS E DISCUSSÃO}

As empresas construtoras, ainda são bastante incipientes nas iniciativas voltadas à gestão adequada dos recursos naturais e dos resíduos depositados no meio ambiente, porém, já existem empresas que utilizam ferramentas e metodologias que as auxiliam na gestão ambiental.

A empresa responsável pela obra, em questão nesse trabalho, utiliza de ferramentas para cumprir um sistema de gestão ambiental, existe uma preocupação com a degradação ambiental e de segurança. Em loco foi possível comprovar o que é divulgado nos meios de comunicação da construtora: Preocupação com o meio ambiente - economia de água; diminuição de resíduos sólidos - Bloco de concreto estrutural: precisão dimensional, permitindo planejar a execução das paredes sem cortes, com poucas quebras e perdas, gerando menos entulho na obra, observa-se na Figura 2. 
Figura 2- Bloco de concreto estrutural

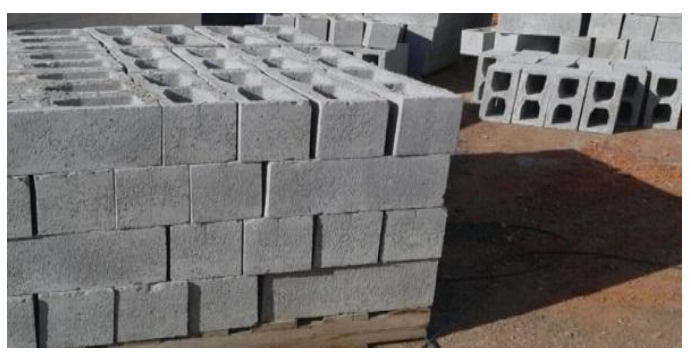

Os resíduos gerados na obra são separados, de acordo com sua capacidade de reutilização, observa-se Figura 3.

Figura 3. Acondicionamento dos resíduos gerados

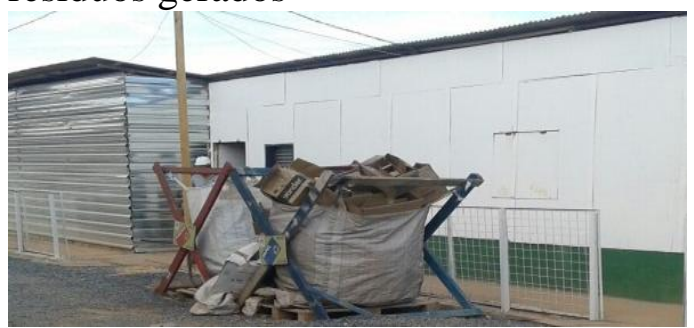

Os resíduos da obra são colocados em caçambas (Figura 4), em locais estratégicos e posteriormente são recolhidos por empresas especializadas que faz a destinação final.

Figura 4- Resíduos

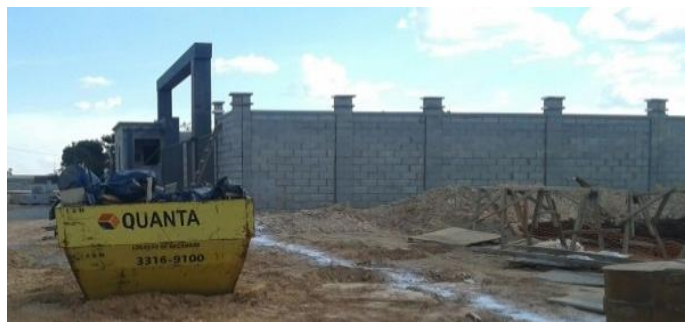

Nos blocos que ainda estão sendo construídos existe um projeto de reutilização das águas pluviais. A água será tratada para posteriormente ser usada para lavar o chão e regar jardins.

De acordo com a NR n.8, os requisitos técnicos devem ser observados nas edificações, para garantir segurança e conforto aos que nelas trabalhem. As rampas e as escadas fixas de qualquer tipo devem ser construídas de acordo com as normas técnicas oficiais e mantidas em perfeito estado de conservação, os pisos, as escadas e rampas devem oferecer resistência suficiente para suportar as cargas móveis e fixas, para as quais a edificação se destina, conforme se observa na Figura 5.

Figura 5. Escadas fíxas

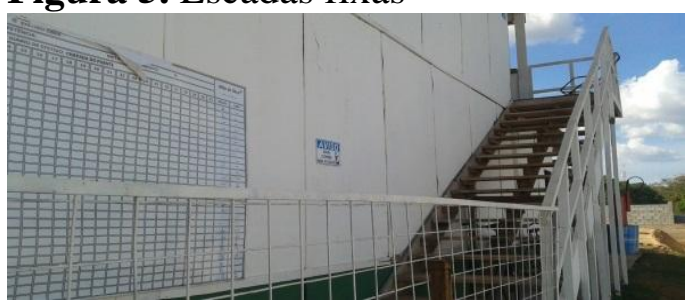

Obedecendo a NR n. 21: Medidas especiais que protejam os trabalhadores contra a insolação excessiva, o calor, o frio, a umidade e os ventos inconvenientes. Nos trabalhos realizados a céu aberto, é obrigatória a existência de abrigos, ainda que rústicos capazes de proteger os trabalhadores contra intempéries, Figura 6.

Figura 6. Abrigos de proteção

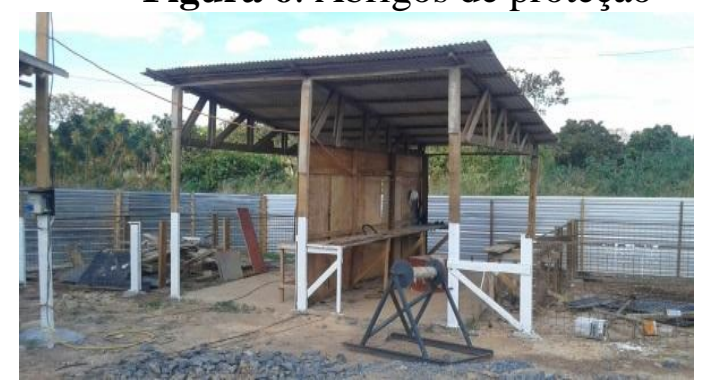

Os locais destinados às privadas serão arejados, com ventilação abundante, mantidos limpos, em boas condições sanitárias e devidamente protegidos contra a proliferação de insetos, ratos, animais e pragas, Figura 7. 
Figura 7 - Condições sanitárias

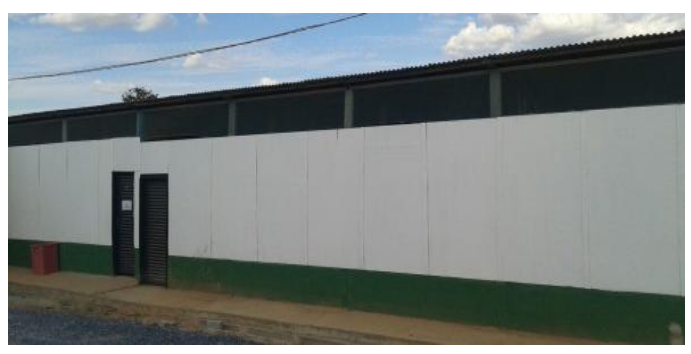

\section{CONSIDERAÇÕES FINAIS}

A elaboração deste artigo teve por intuito mostrar à sociedade que a construção civil tem sua importância consolidada na economia do País, gerando também aspectos favoráveis ao meio ambiente e representando um consumidor potencial de vários tipos de resíduos sólidos de diversos setores. A grande quantidade de matéria-prima e a diversidade de materiais empregados na sua produção ampliam as opções de uso de resíduos com diferentes funções na edificação. Para que a imagem negativa do setor seja minimizada é imprescindível a substituição dos modelos corretivos pelos preventivos, com perspectivas mais amplas, que tenha como princípios básicos a máxima captação dos resíduos gerados nas atividades construtivas, a reciclagem dos resíduos e a alteração de procedimentos e culturas. Porém, a implantação dessas medidas sem um processo contínuo de educação ambiental provavelmente resultará no fracasso desse modelo, pois é exigência a introdução de novos procedimentos, dos quais é possível destacar a prática da coleta seletiva, a reciclagem, a substituição de materiais convencionais pelos reciclados e o incentivo fiscal.

Sendo assim, a construtora cumpre a legislação e ainda possui uma preocupação com o meio ambiente, fazendo uma gestão além das expectativas. Como profissionais da segurança do trabalho foi possível observar que o empreendedor está seguindo as Normas regulamentadoras, conforme o Ministério de Trabalho e Emprego.

\section{REFERÊNCIAS BIBLIOGRÁFICAS}

ISO. International Organization for Standardization. Environmental management - the ISO 14000 family of international standards. 2002. Disponível em: Acesso: 10 jun. 2015

CMMAD. Nosso Futuro Comum. RJ, Ed FGV. 1988.

DEGANI, C. M. Sistemas de gestão ambiental em empresas construtoras de edifícios. São Paulo, 2003.

LAYRARGUES, P. P. Do eco desenvolvimento ao desenvolvimento sustentável: evolução de um conceito? Revista Proposta, v. 25, n. 71, p. 5-10, 1997.

KRAEMER, Maria Elisabeth Pereira. Contabilidade e Gestão Ambiental, 2 ${ }^{\mathrm{a}}$ ed. São Paulo: Atlas, 2004.

MAIA, A. G.; PIRES, P. S. Uma compreensão da sustentabilidade por meio dos níveis de complexidade das decisões organizacionais. RAM, Revista de Administração Mackenzie v. 12 n.3, São Paulo, Junho 2011.

MEYER, M. M. Gestão ambiental no setor mineral: um estudo de caso. 2000. Dissertação (Mestrado em Engenharia da Produção) - Universidade Federal de Santa Catarina, Florianópolis.

Ministério do Trabalho e EmpregoMTE, NR 4 Serviços Especializados em Engenharia de Segurança e em Medicina do Trabalho Publicação D.O.U. Portaria GM n. ${ }^{\circ}$ 3.214, de 08 de junho de 1978 06/07/78. última 
alteração pela Portaria MTE n. ${ }^{\circ}$ 2.018, de 23 de dezembro de 2014 24/12/14

NR 7 - Programa de Controle Médico de Saúde Ocupacional (Redação dada pela Portaria no 24, de 29-12-94 / DOU de 3012-94)

NR 8 Edificações Publicação D.O.U. Portaria GM n. ${ }^{\circ} 3.214$, de 08 de junho de $1978 \quad 06 / 07 / 78$ Atualizações/Alterações Portaria SIT n. ${ }^{\circ}$ 222, de 06

NR 9 Plano de Prevenção de Riscos Ambientais. Publicação D.O.U. Portaria GM n. ${ }^{\circ} 3.214$, de 08 de junho de $\quad 1978 \quad 06 / 07 / 78$ Alterações/Atualizações D.O.U. Portaria SSST n. ${ }^{\circ}$ 25, de 29 de dezembro de 1994 30/12/90

http://www3.mte.gov.br/legislacao/normas_regu lamentadoras/nr 09 at.pdf

NR 18 Condições e Meio Ambiente de Trabalho na Indústria da Construção

Alterada Portaria MTE n. ${ }^{\circ}$ 597, de 07 de maio de 2015, publicada no DOU em 08/05/15

NR 21 Trabalhos a Céu Aberto Publicação D.O.U. Portaria GM n. ${ }^{\circ}$ 3.214, de 08 de junho de 1978 06/07/78 Alterações/Atualizações D.O.U. Portaria GM n. ${ }^{\circ}$ 2.037, de 15 de dezembro de 1999 23/11/79

NR 35, Trabalho em Altura Portaria MTE 593/2014 entra em vigor na data de sua publicação(28.04.2014), Disponível: http://www.guiatrabalhista.com.br /legislacao/nr/nr35.ht

NAHUZ,R.A.M. ISO $14000 \quad e \quad a$ Certificação Ambiental. SP, RAERevista de Administração de Empresas. Nov/Dez 1995. Disponível em: $<$ http://www.scielo.br/pdf/rae/v35n6/a0 7v35n6.pdf> Acesso em julho de 2015.
SOUZA, R. S. Evolução $e$ condicionantes da gestão ambiental nas empresas. REAd- Edição Especial 30, v. 8, n. 6, 2002. 